\title{
Spor Bilimleri Alanında Eğitim Alan Öğrencilerin Kariyer Geleceklerine Yönelik Tutumları
}

\author{
DOI: 10.26466/opus.666255
}

\author{
* \\ Yakup Kılıç* Zeki Coşkuner**- Yunus Emre Karakaya*** \\ * Dr. Öğr. Üyesi, Fırat Üniversitesi, Spor Bilimleri Fakültesi, Elazı ̆̆/TÜRKIYE \\ E-Posta: yakupkilic@firat.edu.tr \\ ORCID: 0000-0003-4889-5571 \\ ** Doç. Dr., Fırat Üniversitesi, Spor Bilimleri Fakültesi, Elazığ/TÜRKIYE \\ E-Posta: zcoskuner@firat.edu.tr \\ ORCID: $\underline{0000-0002-3955-8525}$

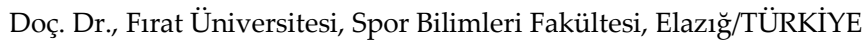 \\ E-Posta emrekarakaya@firat.edu.tr \\ ORCID: $\underline{0000-0002-9858-2103}$
}

\section{Öz}

Bu araştırma, yükseköğretim düzeyinde spor eğitimi alan öğrencilerin kariyer geleceklerine yönelik tutumların ortaya koymak amacıyla yapılmıştır. Araştırma grubu, Fırat Üniversitesi, Sütçü İmam Üniversitesi, Erzincan Üniversitesi ve Sakarya Üniversitelerinde Spor Bilimleri Fakültelerinde spor eğitimi alan rastgele yöntemle seçilmiş 428 öğrenciden oluşmaktadır. Araştırma grubundan verileri elde etmek için "Kariyer Geleceğ $i$ Ölçeğ $i$ " kullanılmış olup, ölçek 3 alt boyut ve 25 ifadeden oluşmaktadır. Elde edilen verilere SPSS 22.0 paket program kullanılarak öncelikle normallik analizi uygulanmıs, sonra parametrik (Independent Sample t-Testi ve Tek Yönlü Varyans Analizi (ANOVA)) ve non-parametrik (Kruskal Wallis Analizi) analizler yapılmıştır. Ayrıca bağıml değiş̧kenler arasında ne düzeyde ve ne yönde bir ilişki olduğunu belirlemek amacıyla Pearson Korelasyon Analizi uygulanmıştır. Araştırma sonucunda, spor eğitimi alan öğrencilerin kariyer geleceklerine yönelik tutumlarında cinsiyet değişkenine göre farklılık görülmüş ( $p<0.05)$; yaş değişkeninde ve ailenin aylık gelirinde ise anlamlı düzeyde farklllık ( $p>0.05)$ görülmemiştir. Yapılan korelasyon analizi sonucunda ise "Kariyer Uyumluluğu" ve "Kariyer İyimserliği" alt boyutlarn $(r=0.592 ; p<0.05)$ arasinda pozitif yönde ve orta düzeyde olduğ $u$ belirlenmiştir. "Kariyer İyimserliği" ve "İş Piyasalarına İlişkin Algzlanan Bilgi" alt boyutları ( $r=0.510$; $p<0.05)$ arasında ise pozitif yönde ve orta düzeyde ilişki olduğu tespit edilmiştir.

Anahtar Kelimeler: kariyer gelecekleri, tutum, spor bilimleri, öğrenci, üniversite 


\title{
Attitudes of Students in Sport Sciences For Career Futures
}

\begin{abstract}
This study was conducted to reveal the attitudes of students who have received sports education at higher education level towards their career futures. The research group consisted of 428 randomly selected students from the Faculty of Sport Sciences at Firat University, Sutcu Imam University, Erzincan University and Sakarya University. The "Career Future Scale" was used to obtain data from the research group, and the scale consisted of 3 sub-dimensions and 25 expressions. Firstly normality analysis was applied by using SPSS 22.0 package program and then parametric (Independent Sample t-Testi and One Way Variance Analysis (ANOVA)) and non-parametric (Kruskal Wallis Analysis) analyzes were performed. In addition, Pearson Correlation Analysis was used to determine the relationship between the dependent variables. As a result of the research, it was seen that the attitudes of the students who took sports education towards their career future according to gender variable ( $p$ $<0.05)$; There was no significant difference in age variable and monthly income of the family $(p>0.05)$. As a result of the correlation analysis, "Career Compliance" and "Career Optimism" sub-dimensions $(r=0.592 ; p<0.05)$ were found to be positive and moderate. There was a positive and moderate relationship between Career Optimism and Below Perceived Information on Labor Markets" $(r=0.510$; $p<0.05$ ).
\end{abstract}

Keywords: career futures, attitude, sports sciences, student, university 


\section{Giriş}

Değişen küresel koşullarda, bireylerin kariyer gelişimleri ve istihdam şartları için uyum yeteneklerini geliştirmeleri önem taşımaktadır. Genç bireyler, kariyer yaşamları boyunca farklı zamanlarda farklı iş rollerine uyum sağlamak ve kariyer geçişleriyle yüzleşmek durumundadırlar (Kanten, 2012). İş ve yaşam tatminini doğrudan etkileyen kariyer seçimi, bireyin bir ömür boyu mutlu yada mutsuz olmasinda temel etkendir. Bu nedenle bireylerin kendilerini çok iyi tanımaları, sektör ve meslekleri iyi araştırmaları ve kendi kişilikleriyle uyumlu meslekleri tercih etmeleri gerekmektedir. Bireyin tüm hayatını etkileyen kariyerinin doğru şekillendirilmesi, hem bireysel hem de örgütsel düzeyde bireyin en çok sahip olduğu kariyer değerlerinin dikkate alınarak uygun mesleki çevrenin belirlenmesi önem taşımaktadır (Adıgüzel ve ark., 2014; Gökdeniz ve Merdan, 2011).

Kariyer, bireyin yaşamı boyunca üstlendiği iş rolüne ilişkin beklentilerini, arzuların gerçekleştirebilmesi için gerekli bilgi, beceri, yetenek ve motivasyonla donatılarak ilerlemesinin sağlanmasıdır (Dündar, 2013). Kariyer, nesnel olarak kişinin yaşamı boyunca çalıştığı pozisyonların tümü, öznel olarak ise iş yaşamına ilişkin oluşan değer, tutum ve davranışlardır. Kariyer, kazanç sağlamak maksadıyla sürdürülen faaliyetler kapsamını içerse de yalnızca gelir elde etmek için sahip olunmaz. Bu yüzden birey yalnızca gelir elde etmek amacıyla değil, toplumsal ve ruhsal gereksinimleri giderme açısından da gereklidir (Eryılmaz ve Mutlu, 2017; Tecimer, 2017; Çurğatay, 2010).

Belirli bir kariyer hedefine ulaşmak için gerekli olan basamaklar zincirini oluşturmak maksadıyla; kendinden, firsatlardan, zorluklardan, seçimlerden ve sonuçlardan haberdar olunan, kariyeriyle ilgili hedefleri belirleyen, iş, eğitim ve gelişmeyle ilgili deneyimleri programlayan önceden tasarlanmış bir süreci kariyer planlaması olarak tanımlamak mümkündür (Delong ve Coombs, 1989). Kariyer planlaması, çalışanla örgütün hedefleri arasında uyumun sağlanması, çalışanın yapmakta olduğu işi daha iyi yapabilmesi için gerekli olan yeterliliklerin geliştirilmesi ve gelecekte üstleneceği muhtemel sorumluluklar için hazır hale getirilmesi sürecidir (Şimşek, 2002). Bu kapsamda, insanlar yetenekleriyle örtüşen bir mesleği seçerek, uygun bir işte çalışmak ve çalışma yaşamları boyunca kariyer planı yaparak daha fazla sorumluluk almak, daha iyi ekonomik koşullara sahip olmak ve terfi etmek istemektedirler (Bingöl, 2014). 
Kariyer planlama konusunda bilinen en önemli yaklaşım, bireysel ve örgütsel yaklaşımdır. Bireysel yaklaşımda birey, kendi kişiliğine uygun yol ve yönü belirleme çabasında olup, birçok faktörden etkilenmektedir. Örgütsel yaklaşımda, kariyer planlaması doğrultusunda biçimlendirilmiş bireysel amaç ve yönelimleri içerik ve felsefe olarak örgütsel amaçlarla birleştirme ilkesi hakimdir. İş piyasasına ve istihdam eğilimlerine ilişkin bilgi ve algılama düzeyinin de yüksek olması başarılı bir kariyer planlama sürecini destekleyecektir. Birey iş ve kişisel yaşantısında meydana gelecek ani değişimlerle başa çıabilecek ve bunu gerçekleştirirken de iyimserliğini kaybetmeden, duygusal iyi oluş halini sürdürebilecektir (Adıgüzel, 2009; Rottinghaus ve ark., 2005). Tuncer (2012) ise bu kapsamda, kariyer planlamasının bireylere sağladığı yararlar şu şekilde ifade etmektedir:

- Bireylerin bir üst pozisyona geçmesinde imkân sağlar.

- Bireylerin ilgi, yetenek, hedef ve değerleri saptamasına yardımcı olur.

- Gelişimlerinin eksiksiz bir şekilde tamamlanmasında önemli rol oynar.

- Birtakım yeteneklerin kullanımı noktasında yol göstericidir.

- Tecrübe ve alınan eğitimler sayesinde örgütsel bir bütünlük sağlamada kolaylık sağlar.

Kariyer tercihi için karar vermek zorunda olan bir birey olup, bu birey seçim için bir takım alternatifleri karşılaştırır ve değerlendirir. Bu süreçte çok çeşitli kriterler ve unsurlar mevcuttur. Bu süreç birçok karar için benzer özellikleri barındırmaktadır. Kariyer yolunda seçilen meslek, bir birey için tüm hayatı içerisindeki en önemli konulardandır. Meslek seçimi beraberinde bir çalışma ve yaşam biçimini de getirmektedir. Birey için bu süreçte başarılı olmak ve kendini kanıtlamak oldukça kritik bir önem taşımaktadır (Özkoç ve ark., 2018; Sarıkaya ve Korshid, 2009).

Dünyada ve Türkiye'de siyasi, sosyal, ekonomik ve teknolojik dönüşümlere paralel olarak spor eğitimi alan bireylerin sayısında gün geçtikçe artma gözlemlenmektedir. Diğer alanlarda olduğu gibi spor eğitimi alan bireylerde de iş bulma ve işte çalışma ortamında yoğun rekabetler yaşanmaktadır. Spor eğitimi alan öğrencilerin gelecekte iş bulmaları ve başarılı oldukları, yeteneklerinin olduğu spor alanında çalışabilmeleri için sürekli olarak yenilikçi ve revize edilmeye uygun kariyer planlamaları yapmaları bir ihtiyaç haline gelmiştir. Bu bağlamda yapılan araştırma, yükseköğretim düzeyinde spor eğitimi alan öğrencilerin kariyer geleceklerine yönelik tutumlarını ortaya koymak amaciyla yapılmıştır. 


\section{Yöntem}

Araştırmanın evrenini Fırat Üniversitesi, Sütçü İmam Üniversitesi, Erzincan Üniversitesi ve Sakarya Üniversitesinde Spor Bilimleri Fakültelerinde spor eğitimi alan öğrenciler oluşturmaktadır. Örneklemini ise rastgele yöntemle seçilmiş 428 öğrenci oluşturmaktadır. Bu üniversitelerde spor eğitimi alan öğrencilerin seçilmesinin nedeni kolay ulaşılabilir olmasıyla alakalıdır.

\section{Veri Toplama Araçlan}

Araştırmada kullanılan "Kariyer Geleceği Ölçeği”, , bireylerde pozitif kariyer planlama tutumlarını değerlendirmek amacıyla Rottinghaus ve ark. (2005)'ları tarafından geliştirilmiştir. Ölçek, "Kariyer Uyumluluğu (11 madde)", "Kariyer İyimserliği (11 madde)" ve "İş Piyasalarına İlişkin Algılanan Bilgi (3 madde)" adı verilen üç alt boyuttan ve toplam 25 maddeden oluşmaktadır. Ölçeğin Türkçe' ye uyarlama çalışması ise Kalafat (2012) tarafından yapılmıştır. Kalafat (2012), ölçeğin Türkçe'ye uyarlaması aşamasında, psikometrik özelliklerini inceleyebilmek amacıyla iç tutarlılık, madde, faktör analizi ve ölçüt bağıntı geçerliği çalışmalarını yapmıştır. Ölçeğin iç tutarlılık analizleri sonucu elde edilen değerler Kariyer Uyumluluğu için 0.84, Kariyer İyimserliği için 0.88, İş Piyasalarına İlişkin Algılanan Bilgi alt boyutu için 0.92 ve toplamda 0.86 bulunarak ölçeğin yeterli güvenirlik düzeylerine sahip olduğu sonucuna ulaşmıştır. Bu araştırmada ise ölçeğin iç tutarlılık analizleri sonucu elde edilen değerler Kariyer Uyumluluğu için 0.81, Kariyer İyimserliği için 0.92, İş Piyasalarına İlişkin Algılanan Bilgi alt boyutu için 0.89 bulunmuştur.

\section{Verilerin Analizi}

Araştırmada verilerin analizi için SPSS 22.0 paket programı kullanılmıştır. Ölçeklerin ve alt boyutlarında elde edilen verilerin normallik varsayımını gerçekleştirip gerçekleştirmediğini görmek için normallik testi yapılmıştır. Daha sonra araştırma grubunun, kişisel değişkenlerine göre dağılımını ortaya koymak amacıyla, bağımsız değişkenlere bağlı farklılaşma düzeyini değerlendirmek için "Independent Sample t-Testi","Tek Yönlü Varyans Analizi (ANOVA)" ve "Kruskal Wallis Analizi (yaş değişkeninde 26 yaş ve üzerinde 
18 kişi olduğu için bu analiz tercih edilmiştir)" yapılmıştır. İstatistiksel anlamlılık derecesi ise $\mathrm{p}<0.05$ olarak kabul edilmiştir. Yine bağımlı değişkenler arasinda ne düzeyde ve yönde bir ilişki olduğunu belirlemek için "Pearson Korelasyon Analizi" yapılmıştır. Bağımlı değişkenler arasındaki korelasyon ilişkileri ise şu kriterlere göre değerlendirilmiştir (Kalaycl, 2006): 0.00-0.25: Çok Zayıf; 0.26-0.49: Zayıf; 0.50-0.69: Orta; 0.70-0.89: Yüksek; 0.90-1.00: Çok Yüksek.

\section{Bulgular}

Araştırmanın amaçları doğrultusunda, yükseköğretim düzeyinde spor eğitimi alan öğrencilerin görüşlerinden elde edilen bulgular aşağıda verilmiştir.

Tablo 1. Araştırma Grubunun Cinsiyet Değişkenine Göre Independent Sample T-Testi Sonuçları

\begin{tabular}{|c|c|c|c|c|c|c|}
\hline Ölçek & Cinsiyet & $\mathbf{N}$ & $\overline{\mathbf{x}}$ & Ss & $t$ & $\mathrm{p}$ \\
\hline \multirow{2}{*}{$\begin{array}{l}\text { Kariyer } \\
\text { Uyumluluğu }\end{array}$} & Erkek & 292 & 3.58 & 0.782 & \multirow{2}{*}{0.877} & \multirow{2}{*}{0.381} \\
\hline & Kadın & 136 & 3.51 & 0.852 & & \\
\hline \multirow{2}{*}{$\begin{array}{l}\text { Kariyer } \\
\text { İyimserliği }\end{array}$} & Erkek & 292 & 3.39 & 0.703 & \multirow{2}{*}{2.247} & \multirow{2}{*}{$0.025^{*}$} \\
\hline & Kadın & 136 & 3.22 & 0.661 & & \\
\hline \multirow{2}{*}{$\begin{array}{l}\text { İş Piyasalarına } \\
\text { İlişkin Algılanan Bilgi }\end{array}$} & Erkek & 292 & 3.32 & 0.968 & \multirow{2}{*}{2.102} & \multirow{2}{*}{$0.036^{\circ}$} \\
\hline & Kadın & 136 & 3.12 & 0.878 & & \\
\hline
\end{tabular}

${ }^{*} p<0.05$

Cinsiyet değişkenine göre sporcu öğrencilerin "Kariyer Geleceği Ölçeği" alt boyutlarından "Kariyer Uyumluluğu" ( $\mathrm{t}=0.877 ; \mathrm{p}>0.05)$ alt boyutunda istatistiksel olarak anlamlı farklılık bulunmamıştır. "Kariyer Iyimserliği" ( $\mathrm{t}=2.247$; $\mathrm{p}<0.05)$ ve "İ̧̧ Piyasalarına İlişkin Algılanan Bilgi" ( $\mathrm{t}=2.102$; $\mathrm{p}<0.05)$ alt boyutlarında ise istatistiksel olarak anlamlı farklılık görülmüştür.

Tablo 2. Araştırma Grubunun Yaş Değişkenine Göre Kruskal Wallis Analizi Sonuçlarn

\begin{tabular}{|c|c|c|c|c|c|c|}
\hline Ölçek & Yaş & $\mathbf{N}$ & $\bar{x}_{\text {sina }}$ & sd & $X^{2}$ & $\mathrm{p}$ \\
\hline \multirow{3}{*}{$\begin{array}{l}\text { Kariyer } \\
\text { Uyumluluğu }\end{array}$} & (a)18-21 yaş & 230 & 210.85 & \multirow{3}{*}{0.804} & \multirow{3}{*}{4.877} & \multirow{3}{*}{0.087} \\
\hline & (b)22-25 yaş & 180 & 212.88 & & & \\
\hline & (c)26yaşveüzeri & 18 & 277.28 & & & \\
\hline \multirow{3}{*}{$\begin{array}{l}\text { Kariyer } \\
\text { İyimserliği }\end{array}$} & (a)18-21 yaş & 230 & 209.95 & & \multirow{3}{*}{0.841} & \multirow{3}{*}{0.657} \\
\hline & (b)22-25 yaş & 180 & 218.64 & \multirow[t]{2}{*}{0.693} & & \\
\hline & (c)26yaşveüzeri & 18 & 231.14 & & & \\
\hline \multirow{3}{*}{$\begin{array}{l}\text { İş Piyasalarına } \\
\text { İlişkin Algılanan Bilgi }\end{array}$} & (a)18-21 yaş & 230 & 218.91 & \multirow{3}{*}{0.944} & \multirow{3}{*}{0.648} & \multirow{3}{*}{0.723} \\
\hline & (b)22-25 yaş & 180 & 209.17 & & & \\
\hline & (c)26yaşveüzeri & 18 & 211.47 & & & \\
\hline
\end{tabular}

${ }^{*} p>0.05$ 
Araştırma grubunda kariyer geleceklerinin yaş gruplarına göre "Kariyer Geleceği Ölçeğ $i$ " alt boyutlarında "Kariyer Uyumluluğu" ( $\left.x^{2}=4.877, p>0.05\right)$, "Kariyer İyimserliği" $\left(x^{2}=0.841, p>0.05\right)$, "İs Piyasalarma İlişkin Algzlanan Bilgi" $\left(x^{2}=0.648, p>0.05\right)$ alt boyutlarında istatistiksel olarak anlamlı farklılık olmadiğı tespit edilmiştir.

Tablo 3. Araştırma Grubunun Ailenin Aylık Gelir Durumu Değişkenine Göre Tek Yönlü Varyans Analizi (ANOVA) Sonuçları

\begin{tabular}{|c|c|c|c|c|c|c|}
\hline Ölçek & Aylık Gelir & $\mathbf{N}$ & $\overline{\mathbf{x}}$ & Ss & $\mathbf{F}$ & p-Değer \\
\hline \multirow{3}{*}{$\begin{array}{l}\text { Kariyer } \\
\text { Uyumluluğu }\end{array}$} & (a) $0-1500 \mathrm{TL}$ & 217 & 3.54 & 0.792 & \multirow{3}{*}{0.131} & \multirow{3}{*}{0.877} \\
\hline & (b) $1500-3000 \mathrm{TL}$ & 144 & 3.58 & 0.823 & & \\
\hline & (c) 3001 TL ve üzeri & 67 & 3.58 & 0.813 & & \\
\hline \multirow{3}{*}{$\begin{array}{l}\text { Kariyer } \\
\text { İyimserliği }\end{array}$} & (a) $0-1500 \mathrm{TL}$ & 217 & 3.33 & 0.683 & \multirow{3}{*}{1.168} & \multirow{3}{*}{0.312} \\
\hline & (b) $1500-3000 \mathrm{TL}$ & 144 & 3.39 & 0.690 & & \\
\hline & (c) 3001 TL ve üzeri & 67 & 3.23 & 0.733 & & \\
\hline \multirow{3}{*}{$\begin{array}{l}\text { İş Piyasalarına } \\
\text { İlişkin Algılanan Bilgi }\end{array}$} & (a) 0-1500 TL & 217 & 3.22 & 0.956 & \multirow{3}{*}{0.345} & \multirow{3}{*}{0.708} \\
\hline & (b) $1500-3000 \mathrm{TL}$ & 144 & 3.31 & 0.914 & & \\
\hline & (c) 3001 TL ve üzeri & 67 & 3.26 & 0.975 & & \\
\hline
\end{tabular}

${ }^{*} p>0.05$

Spor eğitimi alan öğrencilerin "Kariyer Geleceği Ölçeği" alt boyutlarında ailenin aylık gelir değişkenine göre "Kariyer Uyumluluğu" ( $F=0.131$ p>0.05), "Kariyer İyimserliği" ( $F=1.168, \mathrm{p}>0.05)$ ve "İş Piyasalarına İlişkin Algılanan Bilgi" ( $\mathrm{F}=0.345, \mathrm{p}>0.05)$ alt boyutlarında istatistiksel olarak anlamlı farklılık görülmemiştir.

Tablo 4. Kariyer Planlama Tutumları Ölçeğinin Alt Boyutlarna Yönelik Korelasyon Analizi Sonuçları

\begin{tabular}{|c|c|c|c|c|}
\hline Ölçek & Tanımlayıcılar & 1 & 2 & 3 \\
\hline \multirow{3}{*}{$\begin{array}{l}\text { Kariyer } \\
\text { Uyumluluğu (1) }\end{array}$} & $\mathrm{r}$ & 1 & $0.592^{* *}$ & $0.442^{* *}$ \\
\hline & p & - & 0.000 & 0.000 \\
\hline & $\mathbf{N}$ & 428 & 428 & 428 \\
\hline \multirow{3}{*}{$\begin{array}{l}\text { Kariyer } \\
\text { İyimserliği (2) }\end{array}$} & $\mathbf{r}$ & & 1 & $0.510^{* *+}$ \\
\hline & p & & - & 0.000 \\
\hline & $\mathbf{N}$ & & 428 & 428 \\
\hline \multirow{3}{*}{$\begin{array}{l}\text { İş Piyasalarına } \\
\text { İlişkin Algılanan Bilgi (3) }\end{array}$} & $\mathbf{r}$ & & & 1 \\
\hline & $p$ & & & - \\
\hline & $\mathbf{N}$ & & & 428 \\
\hline
\end{tabular}

${ }^{*} p<0.05$

Araştırma grubundan elde edilen veriler sonucunda yapılan korelasyon analizinde "Kariyer Uyumluluğu" ve "Kariyer İyimserliği" alt boyutları arasında 
$(\mathrm{r}=0.592 ; \mathrm{p}<0.05)$ pozitif yönde ve orta düzeyde bir ilişki tespit edilmiştir. Ayrıca, "Kariyer İyimserliği" ve "Kariyer İyimserliği" alt boyutları arasında ise $(\mathrm{r}=0.510 ; \mathrm{p}<0.05)^{\prime \prime}$ pozitif yönde ve orta düzeyde bir ilişki görülmüştür.

\section{Sonuç, Tartışma ve Öneriler}

Araştırma kapsamında yapılan analizler sonucunda elde edilen bulgular aşağıda değerlendirilmiştir:

Araştırma grubunun cinsiyet değişkenine göre kariyer iyimserliği ve iş piyasalarına ilişkin algılanan bilgi alt boyutlarında anlamlı farklılık tespit edilmiştir (Tablo 1). Erkek öğrencilerin kadın öğrencilere göre kariyer geleceğine ilişkin görüşlerinin daha yüksek olduğu görülmüştür. Bu bulgular neticesinde, sporun zor şartlarda ve güce dayalı olarak gerçekleştirilmesi mesleğe atılma ve sporu meslek olarak sürdürme kadın sporcu öğrencilerde kariyer geleceği endişesi oluşturduğu şeklinde yorumlanabilir. Yapılan diğer araştırmalar incelendiğinde şu sonuçlara ulaşılmıştır: Güldü ve Kart (2017), hedef belirleme ve plan oluşturmanın kadınlarda daha yüksek düzeyde olduğunu belirtmiştir. $\mathrm{Bu}$ araştırma bulgusunun aksine araştırma gruplarının kariyer beklentilerinde kadınlarla erkekler arasında kadın öğrencilerin lehine sonuçların olduğu da görülmektedir (Tosun ve Güntaş, 2018; Pişkin, 2011; Taşlıyan ve ark., 2011; Gül ve ark., 2019; Gürdoğan ve Atabey, 2016; Coetzee ve Harry, 2015). Ayrıca, insanların kariyer seçimleri sonrasında kadınların erkeklere göre 4 yıl gibi daha fazla süre aldıkları kararların etkisinde kaldıkları görülmüştür (Howe ve Ives, 2001).

Araştırma grubunda yaş değişkenine yönelik yapılan analizde istatistiksel olarak anlamlı farklılık bulunmamıştır (Tablo 2). Diğer araştırmalar incelendiğinde, araştırmanın bulgularıla benzer sonuçlara ulaşıldığı görülmektedir (Büyükyılmaz ve ark., 2016; Gürdoğan ve Atabey, 2015).

Araştırma grubunda, ailenin aylık gelir değişkenine göre istatistiksel olarak anlamlı farklılık görülmemiştir (Tablo 3). Ailenin gelir düzeyinin az veya fazla olması spor eğitimi alan öğrencilerin kariyer geleceğine yönelik tutumlarında değişiklik oluşturmamıştır. Büyükyılmaz ve ark. (2016)'nın yaptıkları araştırmada da gelir değişkeninin öğrencilerin kariyer planlamaları üzerinde etkisinin olmadığını vurgulamışlardır.

Korelasyon analizi sonucunda "Kariyer Uyumluluğu" ve "Kariyer Iyimserliği" alt boyutlarında pozitif yönde ve orta düzeyde bir ilişki bulunmuştur. 
"Kariyer İyimserliği" ve "İş Piyasalarına İlişkin Algılanan Bilgi" alt boyutlarında da pozitif yönde ve orta düzeyde bir ilişki tespit edilmiştir (Tablo 4). Bu bulgunun spor eğitimi alan öğrencilerin kariyerlerini yapacakları mesleklere daha hazır oldukları, mesleklerinde karşılaştıkları muhtemel problemlere hazır ve hızlı çözüm sunabilecekleri şeklinde yorumlanabilir. Ayrıca aha az karar verme sorunu yaşayacakları, öğrencilerin kariyer geleceği tutumlarında, mesleki gelişimlerinde ve mesleklerinde pozitif etkiler oluşturacağı söylenebilir. Benzer şekilde, Büyükyılmaz ve ark. (2016)'da yaptıkları araştırmada öğrencilerin kariyer planlama algısı çerçevesinde kariyer uyumluluğu algısının en yüksek ortalamaya sahip olduğunu tespit etmişlerdir. İş piyasasına ilişkin algılanan bilgi alt boyutunda ise en düşük ortalamaya sahip alt boyut olduğunu belirtmişlerdir.

Araştırmada, kadın ve erkek öğrencilerin kariyer iyimserlikleri ve iş piyasasına ilişkin algılanan bilgilerinin erkek öğrencilerin lehine anlamlı farklılık oluşturmuştur. Erkek öğrencilerin mesleklerinde daha çok başarılı olacakları ve bu başarıların sürdürmek için daha çok çaba harcayacakları sonucuna ulaşılmıştır. Erkek öğrencilerin iş piyasasına ilişkin algılanan bilgi puanlarının yüksek olması meslekleriyle ilgili piyasayı daha çok takip ettikleri sonucuna varılabilir. Öğrencilerin yaş durumlarına yönelik tutumlarının benzer olduğu görülmüştür. Yaş değişkeninin öğrencilerin kariyer gelecekleri tutumları üzerinde etkisinin olmadığı belirlenmiştir. Öğrencilerin aldıkları spor disiplini, mücadele anlayışı ve sporun kazandırdığı özgüvenden dolayı ailelerinin gelir durumlarının kariyer gelecekleri üzerinde bir etkisinin olmadığı sonucuna ulaşılmıştır. Öğrencilerin kariyer geleceklerine yönelik tutumlarında, kariyer uyumları ve kariyer iyimserliklerinin olumlu olduğu görülmüştür. İş piyasasına ilişkin bilgilerinin ise iş istihdamı, iş piyasası ve politikaları hakkında öğrencilerin yeterli bilgiye sahip olmadıkları görülmüştür. Sonuç olarak, öğrencilerin kariyer geleceği tutumlarının daha da iyileştirilebilmesi için kurumlarda danışmanlık hizmeti sunacak yapılar (kariyer günleri, yurtdışı tanıtım toplantıları gibi) oluşturulmalıdır. Fakülte bünyesinde öğrencilerin kariyer geleceklerine yönelik öğrenme ortamlarının oluşturulması sağlanmalıdır. Öğretim elemanları tarafından öğrencilerin ilk yıllardan itibaren alanla ilgili sempozyum, kongrelere ve dil öğrenmelerine yönlendirilecek danışmanlık rolleri üstlenilmelidir. Ayrıca, bu araştırma sadece dört 
üniversitedeki öğrencileri kapsamaktadır. Farklı alanlarda ve farklı üniversitelerdeki spor eğitimi alan öğrenciler üzerinde uygulanıp, farklı bulgulara ulaşılabilir. 


\title{
EXTENDED ABSTRACT
}

\section{Attitudes of Students in Sport Sciences For Career Futures}

\author{
* \\ Yakup Kılıç - Zeki Coşkuner - Yunus Emre Karakaya \\ Firat University
}

The number of individuals receiving sports education is increasing day by day in parallel with political, social, economic and technological transformations in the World and Turkey. There are intense competitions in the job finding and work environment for individuals studying sports as in other areas. It has become a necessity for students studying sports to pursue innovative and revised career plans in order to find jobs in the future and to work in the field of sports where they are successful and have skills. The research was conducted to demonstrate the attitudes of students studying sports at higher education level towards their career future in this context.

The research group consists of 428 randomly selected students who study at Firat University, Sütcü Imam University, Erzincan University and Sakarya University Faculties of Sports Sciences.

The "Career Future Scale" used in the research was developed by Rottinghaus and colleagues (2005) to evaluate positive career planning attitudes in individuals. The scale consists of three sub-dimensions and a total of 25 items, called "Career Compatibility (11 articles)", "Career optimism (11 articles)" and "Perceived Information on Business Markets ( 3 articles)". The adaptation of Turkish version of the scale was made by Kalafat (2012).

Normality testing was performed firstly to see if the scales and the data obtained in their sub-dimensions performed the assumption of normality in this study. Then, to evaluate the level of differentiation based on arguments, "Independent Sample t-Test", "One-Way Variance Analysis (ANOVA)" and "Kruskal Wallis Analysis" in order to determine the distribution of the research group according to their personal variables Analysis" was done. The degree of statistical significance was accepted as $\mathrm{p}<0.05$. "Pearson Correlation Analysis" was performed to determine what level and di- 
rection there is a correlation between dependent variables. Correlation relationships between dependent variables were evaluated according to the following criteria (Kalayci, 2006): 0.00-0.25: Very Weak; 0.26-0.49: Weak; 0.500.69: Medium; 0.70-0.89: High; 0.90-1.00: Very high.

There was no statistically significant difference in the sub-dimension of "Career Compatibility" ( $t=0.877$; $>>0.05$ ) from the "Career Future Scale" subdimensions of sports students according to the gender variable. There was a statistically significant difference in the sub-dimensşon of "career optimism" $(\mathrm{t}=2,247 ; \mathrm{p}<0.05)$ and "Perceived Information on Job Markets" $(\mathrm{t}=2,102 ;$ p.0.05) (Table 1).

"Career Compatibility" ( $\mathrm{x} 2=4,877, \mathrm{p}>0.05)$, "Career optimism" ( $22=0.841$, $\mathrm{p}>0.05)$, "Perceived Information on Job Markets" ( $\mathrm{x} 2=0.648, \mathrm{p}>0.05)$ in subdimensions of "Career Future Scale" according to age groups of career futures in the research group there was no statistically significant difference in dimensions (Table 2).

"Career Compatibility" ( $\mathrm{F}=0.131 \mathrm{p}>0.05)$, "Career Optimism" ( $\mathrm{F}=1.168$, $\mathrm{p}>0.05)$ and "Perceived Information on Job Markets" ( $\mathrm{F}=0.345, \mathrm{p}>0.05)$ according to the family's monthly income variable in the "Career Future Scale" of students studying sports there was no statistically significant difference in its sub-dimension (Table 3).

Correlation analysis of the data obtained from the research group revealed a positive way and moderate level between "Career Compatibility" and "Career optimism" sub-dimensions ( $\mathrm{r}=0.592 ; \mathrm{p}<0.05)$. In addition, a positive way and moderate level relationship was observed between "Career optimism" and "Career optimism" sub-dimensions ( $\mathrm{r}=0.510$; $\mathrm{p}<0.05)$ " (Table 4).

In the study, "career optimism" of male and female students and "perceived information on the job market" had a significant difference in favor of male students. It has been concluded that male students will be more successful in their profession and will work harder to sustain them. It can be concluded that male students have a high perceived information score on the job market and follow the market in their profession more. It has been observed that the attitudes of the students towards their age status are similar. It was determined that the age variable had no effect on students' career future attitudes. Due to the sports discipline, struggle and self-confidence gained by sports, it has been concluded that the income status of the students' families has no effect on their career future. The attitudes of the 
students towards their career future, their career compatibility and career optimism have been shown to be positive. It has been observed that the students do not have sufficient knowledge about job employment, job market and policies. Consequently, structures (career days, overseas promotional meetings) should be established to provide consultancy services in institutions in order to further improve the career future attitudes of students. It should be ensured that learning environments for the career future of the students should be established, within the faculty. The faculty members should take on consultancy roles to be directed to symposiums, congresses and language learning in students' fields from the first years of the them. In addition, this research covers only students from four universities. It can be applied on students studying sports in different fields and universities and different findings can be reached.

\section{Kaynakça / References}

Adıgüzel, O. (2009). Shein'in kariyer çapaları perspektifinde süleyman demirel üniversitesi iibf öğrencilerinin kariyer değerlerine ilişkin bir araştırma. Süleyman Demirel Üniversitesi İ̈BF Dergisi, 14 (2), 277-292.

Adıgüzel, O. ve Erdoğan, A. (2014). Anne roe ve holland'ın kişilik kuramları ile shein'in kariyer değerlerinin içerik analizi yöntemiyle değerlendirilmesi. Uluslararası Alanya İşletme Fakültesi Dergisi, 6 (3),15-25.

Aytaç, S. ve Keser, A. (2017). Çalışma yaşamında kariyer planlaması yönetimi geliştirilmesi ve sorunları. 3. Baskı, Kocaeli: Umuttepe Yayınları.

Bingöl, D. (2014). İnsan kaynakları yönetimi. 9. Baskı, Beta Basım Anonim Şirketi, İstanbul.

Büyükyılmaz, O., Ertaç, S. ve Gökerik, M. (2016). Öğrencilerin kariyer planlama tutumlarının demografik faktörler açısından değerlendirilmesi: Karabük üniversitesi işletme fakültesi öğrencileri üzerine bir araştırma. İnsan ve Toplum Bilimleri Araştırmaları Dergisi, 5 (7), 2065-2076.

Coetzee, M. ve Harry, N. (2015). Gender and hardiness as predictors of career adaptability: an explotary study among black call centre agents. South African Journal of Psychology, 45 (1), 81-92.

Çurğatay, V. (2010). Üniversite sinavina girecek öğrencilerin meslek seçimini etkileyen sosyo-kültürel faktörler. Yüksek Lisans Tezi, İnönü Üniversitesi.

Delong, T.J. ve Coombs, C.G. (1989). The role of the principal in the career development of teachers. Journal of Career Development, 15 (3), 206. 
Dündar, G. (2013). Kariyer geliştirme. (S. Öz, ed.) İnsan Kaynakları Yönetimi içinde (s. 268-298.) İstanbul: Beta.

Eryılmaz, A. ve Mutlu, T. (2017). Yaşam boyu gelişim yaklaşımı perspektifinden kariyer gelişimi ve ruh sağlığı. Psikiyatride Güncel Yaklaşımlar, 9(2), 227-249.

Gökdeniz, İ. ve Merdan, E. (2011). Kişilik ile kariyer seçimi arasındaki ilişkinin incelenmesi. Aksaray Üniversitesi İIBF Dergisi, 3(2), 23-36.

Gül, H., Maksüdünov, A., Yamaltdinova, A. ve Abdildaev, M. (2019). Öğrencilerin demografik özelliklerinin kariyer uyumluluğu ve iyimserliği ile ilişkisi: Kırgızistan örneği. KMÜ Sosyal ve Ekonomik Araştırmalar Dergisi, 21(36), 34-46.

Güldü, Ö. ve Kart, M.E. (2017). Kariyer planlama sürecinde kariyer engelleri ve kariyer geleceği algılarının rolü. Ankara Üniversitesi Spor Bilimleri Fakültesi Dergisi, 72(2), 377-400.

Gürdoğan, A. ve Atabey, S. (2015). Öğrencilerin meslek stajından memnuniyet düzeylerinin kariyer hedeflerine etkisi. Ekonomi ve Yönetim Araştırmaları Dergisi, 4(1), 91-113.

Howe, A. ve Ives, G. (2001). Does community-based experience alter career preference? new evidence from a prospective longitudinal cohort study of undergraduate medical students, Medical Education, 35, 391-397.

Kalafat, T. (2012). Türk örneklemi için psikometrik özelliklerinin incelenmesi. Türk Psikolojik Danışma ve Rehberlik Dergisi, 4(38), 169-179.

Kalaycı, Ş. (2006). SPSS uygulamalı çok değişkenli istatistik teknikleri. Asil Publication Distribution, Ankara.

Karasar, N. (2009). Bilimsel araştırma yöntemi: kavramlar, ilkeler, teknikler. 7. Printing, 3A Research Education, Danışmanlık Ltd. Com., Ankara.

Kanten, S. (2012). Kariyer uyum yetenekleri ölçeği: geçerlilik ve güvenilirlik çalışması. Süleyman Demirel Üniversitesi Sosyal Bilimler Enstitüsü Dergisi, 2 (16),191-205.

Rottinghaus, P. J., Day, S. X. ve Borgen, F. H. (2005). The career futures inventory: a measure of careerrelated adaptability and optimism. Journal of Career Assessment, 13 (1), 3-24.

Rottinghaus, Patrick. J., Susan X.D. ve Fred H. B. (2005). The career futures inventory: a measure of career-related adaptability and optimism, Journal of Career Assessment, 13, 3-24.

Özkoç, H. H., Marangoz, M., Aydın ve A. E. (2018). Öğrencilerin kariyer alternatiflerini etkileyen faktörler ve girişimcilik eğitimi. Uluslararası İktisadi ve İdari Bilimler Dergisi, 4(1), 98-119. 
Tecimer, S. (2017). Lise öğrencilerinin kariyer gelişiminde aile rolünün farklı değişkenlere göre incelenmesi. Yüksek Lisans Tezi, Doğu Akdeniz Üniversitesi.

Tosun, Ü. ve Güntaş, S. (2018). Üniversite öğrencilerinin kariyer beklentileri ve empati eğilimleri: KKTC Örneği. European Journal of Managerial Research Dergisi, 2(2), 23-38.

Tunçer, P. (2012). Değişen insan kaynakları yönetimi anlayışında kariyer yönetimi. Ondokuz Mayıs Üniversitesi Eğitim Fakültesi Dergisi, 31(1), 215-218.

Pişkin, M. (2011). Kariyer gelişim sürecini etkileyen faktörler. (B. Yeşilyaprak Ed.) Mesleki Rehberlik ve Kariyer Danışmanlı̆̆: Kuramdan Uygulamaya,(s.43-78.)., Ankara: Pegem Akademi.

Taşlıyan, M., Arı, N. ve Duzman, B. (2011). İnsan kaynakları yönetiminde kariyer planlama ve kariyer yönetimi; İ̈BF öğrencileri üzerinde bir alan araştırması. Organizasyon ve Yönetim Bilimleri Dergisi, 3(2), 25-33.

Sarıkaya, T. ve Khorshid, L. (2009), Üniversite öğrencilerinin meslek seçimini etkileyen etmenlerin incelenmesi: üniversite öğrencilerinin meslek seçimi, Türk Ĕ̆itim Bilimleri Dergisi, 7(2), 393-423.

Şimssek, M.S, (2002). Yönetim ve organizasyon. 7. Baskı, Konya: Günay Ofset.

\section{Kaynakça Bilgisi / Citation Information}

Kılıç, Y., Coşkuner, Z E. ve Karakaya, Y. E. (2020). Spor bilimleri alanında eğitim alan öğrencilerin kariyer geleceklerine yönelik tutumları. OPUS-Uluslararası Toplum Araştırmaları Dergisi, 15(23), 2064-2078. DOI: 10.26466/opus.666255 